\section{The buzz about BAFF}

David L. Vaux

\section{Commentary}

See related article, pages 59-68.

The Walter and Eliza Hall Institute, Royal Parade Parkville, Victoria 3050, Australia.

Phone: 61-3-9345-2544; Fax: 61-3-9347-0852; E-mail: vaux@wehi.edu.au.

J. Clin. Invest. 109:17-18 (2002). DOI:10.1172/JCI200214780.

In idle moments, people who treat autoimmune diseases such as systemic lupus erythematosus (SLE), rheumatoid arthritis (RA), and Sjögren syndrome (SS) dream of finding the diseases' Achilles heel: a protein that plays some causative role, is required for disease persistence, and can be targeted therapeutically without causing widespread side effects. Experiments on BAFF (also known as BLyS, TALL-1, THANK or zTNF4) (1-4), a new member of the TNF family of cytokines, are generating enormous excitement because they suggest that these dreams just might come true. Here, at last, is an example of a molecule that appears to be involved in common human autoimmune diseases, rather than just the ever-so-rare eponymous syndromes (5-8). Moreover, experiments in animals suggest that therapies based on antagonizing BAFF may make a real difference clinically $(6,9-12)$.

There are many mouse models of SLE, for example, featuring high levels of anti-DNA antibodies, depositions of immune complexes, and organ failure. These include Bcl-2 transgenic mice (13), mice lacking the Bcl-2 antagonist Bim (14), mice with low expression of CD95 (Fas/APO-1; the product of the mouse lpr gene) (15), and mice lacking genes lyn or fyn $(16,17)$, among others. Disappointingly, mutation or aberrant expression of these genes has only rarely been found in humans with common autoimmune syndromes (18). In contrast, elevated levels of BAFF have now been found in humans with SLE, RA, and SS, as well as in both $l p r$ and $\mathrm{NZB} / \mathrm{WF}_{1}$ mice (5-8).

BAFF is made in both membranebound and soluble forms by myeloid cells and dendritic cells, as well as by some $T$ cells (reviewed in ref. 19). It is most closely related to APRIL/ TRDL- $1 \alpha$, another TNF family member implicated in growth of tumor cells (20). Both BAFF and APRIL can bind to either of the receptors BCMA and TACI, but only BAFF binds another receptor, BAFF-R/BR3, that is expressed on the surface of $B$ cells $(21,22)$ (Figure 1). When the BAFF receptor gene is mutated, as occurs in $\mathrm{A} / \mathrm{WySnJ}$ mice, peripheral B cells are absent $(21,22)$, indicating that BAFF signaling is required for the production or maintenance of these cells. Ligation of BAFF-R seems not to affect proliferation, but rather to promote B cell survival, perhaps by increasing expression of the antiapoptotic protein $\mathrm{Bcl}-2(23,24)-\mathrm{a}$ possibility that would fit nicely with the observations of autoimmunity in Bcl-2 transgenic mice (13).

Injection of recombinant BAFF into mice enhances both Ig levels and mature B cell numbers (25). The B cell

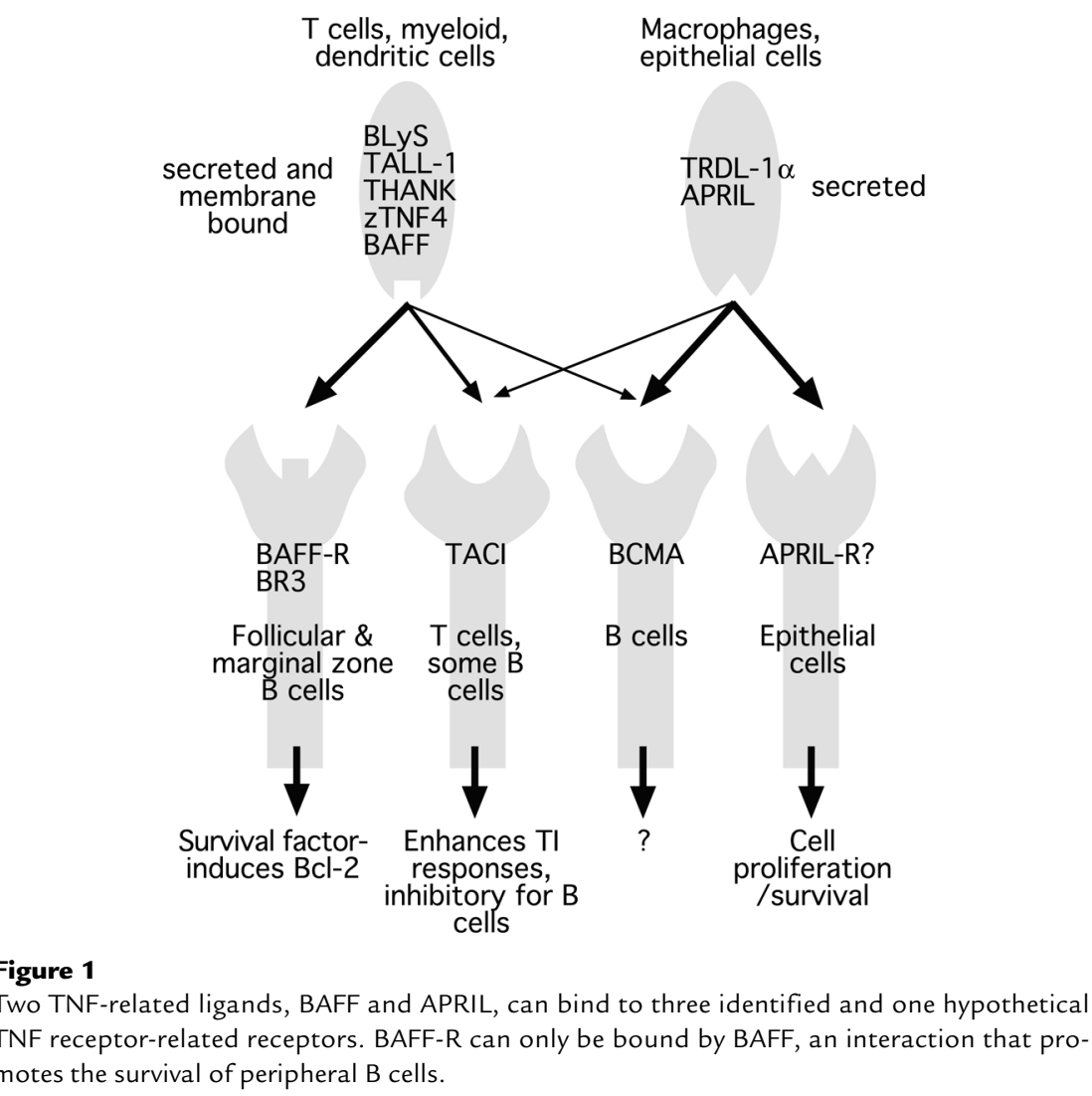

Figure 1

Two TNF-related ligands, BAFF and APRIL, can bind to three identified and one hypothetical TNF receptor-related receptors. BAFF-R can only be bound by BAFF, an interaction that promotes the survival of peripheral $B$ cells.

population is also increased when BAFF is continuously elevated, as in BAFF transgenic mice. These mice are prone to an SLE-like syndrome, with raised levels of circulating immune complexes and anti-DNA autoantibodies, and Ig deposits in their kidneys $(6,26,27)$. Moreover, as described by Groom et al. in this issue of the JCI, they also develop and eventually succumb to a disease like SS, with severe inflammation of the salivary glands (7). Thus, overproduction of BAFF is sufficient to cause the development of two autoimmune diseases in vivo.

Blocking BAFF in vivo confirms that it is required for persistence of mature $B$ cells and generation of specific antibody responses. Mice treated with TACI-Fc protein, which binds to BAFF and prevents it from engaging its 
receptor, fail to produce antigen-specific IgM and IgG1 antibodies or to develop germinal centers in the spleen following immunization (11). Similarly, specific Ig production is diminished in immunized mice treated with a BR3-Fc fusion protein that competes with BAFF-R for circulating BAFF (12); mice injected with a BCMA-Ig protein exhibit greatly reduced numbers of peripheral B cells (28). Most exciting of all, BAFF may be necessary for persistence of autoimmune disease. In SLE-prone NZB/WF $\mathrm{WF}_{1}$ mice, treatment with a TACI-Ig fusion protein inhibits development of proteinuria and prolongs survival (6). Similarly, injected TACI-Fc could prevent onset and reduce signs of disease in mouse models of SLE and collageninduced arthritis (10).

Thus, in mice, increased BAFF is associated with autoimmune diseases; elevated levels of BAFF are sufficient to cause autoimmunity; BAFF is required for specific $B$ cell responses and autoimmunity; and BAFFblocking reagents reduce disease incidence and severity in vivo. Because elevated BAFF is also associated with autoimmune diseases in humans SLE, SS, and RA, and possibly more to follow - BAFF-blocking reagents hold great promise in the treatment of autoimmunity in humans.

1. Moore, P.A., et al. 1999. BLyS: member of the tumor necrosis factor family and B lymphocyte stimulator. Science. 285:260-263.
2. Schneider, P., et al. 1999. BAFF, a novel ligand of the tumor necrosis factor family, stimulates B cell growth. J. Exp. Med. 189:1747-1756.

3. Shu, H.B., Hu, W.H., and Johnson, H. 1999. TALL-1 is a novel member of the TNF family that is down-regulated by mitogens. J. Leukoc. Biol. 65:680-683.

4. Mukhopadhyay, A., Ni, J., Zhai, Y.F., Yu, G.L., and Aggarwal, B.B. 1999. Identification and characterization of a novel cytokine, THANK, a TNF homologue that activates arpoptosis, nuclear factor-kappa B, and c-Jun NH2-terminal kinase. J. Biol. Chem. 274:15978-15981.

5. Cheema, G.S., Roschke, V., Hilbert, D.A., and Stohl, W. 2001. Elevated serum B lymphocyte stimulator levels in patients with systemic immune-based rheumatic diseases. Arthritis Rheum. 44:1313-1319.

6. Gross, J.A., et al. 2000. TACI and BCMA are receptors for a TNF homologue implicated in B-cell autoimmune disease. Nature. 404:995-999.

7. Groom, J., et al. 2002. Association of BAFF/BLyS overexpression and altered B cell differentiation with Sjögren's syndrome. J. Clin. Invest. 109:59-68. DOI:10.1172/JCI200214121.

8. Zhang, J., et al. 2001. A role for B lymphocyte stimulator in systemic lupus erythematosus. $J$. Immunol. 166:6-10.

9. Gross, J.A., et al. 2001. TACI-Ig neutralizes molecules critical for B cell development and autoimmune disease: impaired B cell maturation in mice lacking BLyS. Immunity. 15:289-302.

10. Wang, H., et al. 2001. TACI-ligand interactions are required for $\mathrm{T}$ cell activation and collageninduced arthritis in mice. Nat. Immunol. 2:632-637.

11. Xia, X.Z., et al. 2000. TACI is a TRAF-interacting receptor for TALL-1, a tumor necrosis factor family member involved in B cell regulation. J. Exp. Med. 192:137-143.

12. Yan, M.H., et al. 2000. Identification of a receptor for BLyS demonstrates a crucial role in humoral immunity. Nat. Immunol. 1:37-41.

13. Strasser, A., et al. 1991. Enforced BCL2 expression in B-lymphoid cells prolongs antibody responses and elicits autoimmune disease. Proc. Natl Acad. Sci. USA. 88:8661-8665.

14. Bouillet, P., et al. 1999. Proapoptotic Bcl-2 relative bim required for certain apoptotic responses, leukocyte homeostasis, and to preclude autoimmunity. Science. 286:1735-1738.
15. Watanabe, F.R., Brannan, C.I., Copeland, N.G., Jenkins, N.A., and Nagata, S. 1992. Lymphoproliferation disorder in mice explained by defects in Fas antigen that mediates apoptosis. Nature. 356:314-317.

16. Takahashi, T., et al. 1997. Suppression of autoimmune disease and of massive lymphadenopathy in $\mathrm{MRL} / \mathrm{Mp}-\mathrm{lpr} / \mathrm{lpr}$ mice lacking tyrosine kinase Fyn (p59fyn). J. Immunol. 159:2532-2541.

17. Hibbs, M.L., et al. 1995. Multiple defects in the immune system of lyn-deficient mice, culminating in autoimmune disease. Cell. 83:301-311.

18. Vaux, D.L., and Flavell, R.A. 2000. Apoptosis genes and autoimmunity. Curr. Opin. Immunol. 12:719-724

19. Laabi, Y., and Strasser, A. 2000. Lymphocyte survival: ignorance is BLys. Science. 289:883-884.

20. Ware, C.F. 2000. APRIL and BAFF connect autoimmunity and cancer. J. Exp. Med. 192:F35-F37.

21. Thompson, J.S., et al. 2001. BAFF-R, a newly identified TNF receptor that specifically interacts with BAFF. Science. 293:2108-2111.

22. Yan, M.H., et al. 2001. Identification of a novel receptor for $B$ lymphocyte stimulator that is mutated in a mouse strain with severe B cell deficiency. Curr. Biol. 11:1547-1552.

23. Do, R.K.G., et al. 2000. Attenuation of apoptosis underlies B lymphocyte stimulator enhancement of humoral immune response. J. Exp. Med. 192:953-964.

24. Batten, M., et al. 2000. BAFF mediates survival of peripheral immature B lymphocytes. J. Exp. Med. 192:1453-1465.

25. Parry, T.J., et al. 2001. Pharmacokinetics and immunological effects of exogenously administered recombinant human B lymphocyte stimulator (BLyS) in mice. J. Pharmacol. Exp. Ther 296:396-404.

26. Mackay, F., et al. 1999. Mice transgenic for BAFF develop lymphocytic disorders along with autoimmune manifestations. J. Exp. Med. 190:1697-1710

27. Khare, S.D., et al. 2000. Severe B cell hyperplasia and autoimmune disease in TALL-1 transgenic mice. Proc. Natl. Acad. Sci. USA. 97:3370-3375.

28. Thompson, J.S., et al. 2000. BAFF binds to the tumor necrosis factor receptor-like molecule B cell maturation antigen and is important for maintaining the peripheral B cell population. $J$. Exp. Med. 192:129-135. 